\title{
Paragog of Rosé's Caption on Instagram
}

\section{Adib Rifqi Setiawan}

Rosénator Warrior

rosenatorwarrior@gmail.com

\begin{abstract}
The present paper seeks to analyze Rosé's caption on her instagram @roses_are_rosie based on linguistics's concept named paragoge.
\end{abstract}

Keywords: instagram, linguistics, paragoge, Rosé 